\title{
The non-adrenergic imidazoline-1 receptor protein Nischarin is a key regulator of astrocyte glutamate uptake
}

Short title: Nischarin regulates glutamate uptake

Swati Gupta*, Narges Bazargani, James Drew*, Souvik Modi, Hélène Marie*, David Attwell and Josef T. Kittler

Department of Neuroscience, Physiology and Pharmacology, University College London, Gower Street, WC1E 6BT, London, UK

*Current Affiliations:

Swati Gupta - Nash Family Department of Neuroscience and Friedman Brain Institute, The Icahn School of Medicine at Mount Sinai, New York, NY 10029

James Drew - Beatson Institute for Cancer Research, Garscube Estate, Switchback Road, Bearsden, Glasgow G61 1BD, UK

Hélène Marie - Université Côte d'Azur, CNRS UMR 7275, IPMC, Valbonne, France 


\section{Summary}

Astrocytic GLT-1 is the main glutamate transporter involved in glutamate buffering in the brain, pivotal for glutamate removal at excitatory synapses to terminate neurotransmission and for preventing excitotoxicity. We show here that the surface expression and function of GLT1 can be rapidly modulated through the interaction of its $\mathrm{N}$-terminus with the nonadrenergic imidazoline-1 receptor protein, Nischarin. The phox domain of Nischarin is critical for interaction and internalization of surface GLT-1. Using live super-resolution imaging, we found that glutamate accelerated Nischarin-GLT-1 internalization into endosomal structures. The surface GLT-1 level increased in Nischarin knockout astrocytes, and this correlated with a significant increase in transporter uptake current. Furthermore, Nischarin knockout in astrocytes is neuroprotective against glutamate excitotoxicity. These data provide new molecular insights into regulation of GLT-1 surface level and function and suggest novel drug targets for the treatment of neurological disorders.

\section{Highlights}

- The phox domain of Nischarin interacts with the N-terminal tail of the main astrocyte glutamate transporter, GLT-1.

- Nischarin promotes internalization of GLT-1 to endosomes.

- Glutamate modulates GLT-1 surface levels via regulation of the Nischarin-GLT-1 interaction.

- Genetic loss of Nischarin significantly increases GLT-1 surface expression, resulting in increased glutamate transport currents and enhanced neuroprotection. 


\section{Introduction}

Glutamate transport into cells is mediated by excitatory amino acid transporters (EAATs). Of the five EAAT subtypes found in the CNS, EAAT2/GLT-1 is predominantly expressed in astrocytes and is a major means for glutamate clearance from the extracellular space (Danbolt, 2001). Glutamate buffering through transporter binding helps to maintain a low extracellular glutamate concentration that facilitates termination of fast excitatory synaptic transmission (Diamond and Jahr, 1997, Wadiche et al., 1995a, Wadiche et al., 1995b, Tong and Jahr, 1994). Moreover, lateral diffusion of surface GLT-1 can also regulate glutamate clearance and thus shape glutamatergic neurotransmission (Al Awabdh et al., 2016, Murphy-Royal et al., 2015). The transporters have a long transport cycle ( 70 msec) (Wadiche et al., 1995a) compared to the time scale of glutamate presence at the synapse $(\sim 1 \mathrm{msec})$ (Barbour and Hausser, 1997). However, despite this long transport cycle, efficient glutamate clearance occurs during synaptic activity due to the high surface density of transporters (Danbolt, 2001). A low extracellular glutamate concentration (below the submicromolar level that tonically activates NMDA receptors) is also crucial to prevent excitotoxic cell death (Choi et al., 1987, Choi, 1987). Thus, control of GLT-1 density on the astrocyte surface via molecular mechanisms modulating its intracellular trafficking is crucial for normal synaptic physiology and prevention of excitotoxicity.

Four isoforms of GLT-1 have been identified, which exhibit similar functional properties and oligomerize to form homomeric and heteromeric GLT-1 pools. However, the GLT-1 isoforms differ in their $\mathrm{N}$ - and $\mathrm{C}$-termini, allowing for interaction with different intracellular proteins and offering an opportunity for differential regulation of the isoforms during physiological and pathological conditions (Peacey et al., 2009). So far, scaffolding proteins, such as PSD-95, PICK-1 and MAGI-1 have been shown to interact with the PDZ domain containing C-terminus of the GLT-1b isoform (Underhill et al., 2015, Sogaard et al., 2013, Zou et al., 2011, GonzalezGonzalez et al., 2008). Here, we have identified the non-adrenergic imidazoline-1 receptor protein Nischarin, as a novel physiological GLT-1 N-terminus interacting protein in astrocytes. Nischarin is a cytoplasmic protein that shows a diverse set of functions, including regulation of the cytoskeletal network (through Rac1), interaction with endosomes (via its phox domain), and regulation of receptor (mu opioid and integrin $\alpha_{5}$ receptors) surface levels (Alahari et al., 
2000, Keller et al., 2017, Li et al., 2016, Kuijl et al., 2013, Alahari et al., 2004, Alahari, 2003, Dong et al., 2017).

Here, we report that the Nischarin phox domain is sufficient for interaction with a 30 amino acid stretch of the GLT-1 N-terminus. Super-resolution imaging revealed that glutamate drives internalization of GLT-1 in a Nischarin-dependent pathway. In addition, Nischarin knockout $\left(\mathrm{Nisch}^{\mathrm{KO}}\right)$ animals exhibit increased astrocytic GLT-1 surface expression that correlates with increased transporter current and enhanced neuroprotection. Together, these data suggest a novel mechanism for how glutamatergic signalling is regulated in the central nervous system under both physiological and pathological conditions.

\section{Results}

\section{GLT-1 and Nischarin interact in vivo}

A yeast two-hybrid screen (Y2H) with the GLT-1 N-terminus identified a clone that encoded the phox domain of the Nischarin protein as a novel interactor for the GLT-1 protein (Marie et al., 2002). Next, a coimmunoprecipitation assay was performed in COS cells co-transfected with GLT-1a (tagged in the extracellular loop with a V5 epitope) and GFP-tagged Nischarin (Nisch) lacking the phox domain (GFP-Nisch $\Delta$ phox), or Nischarin's phox domain alone (GFPphox) or a GFP control (Fig. 1A). We found that the GFP-phox domain construct, but not the GFP-Nisch $\Delta$ phox, co-precipitated with GLT-1 (Fig. 1A), suggesting that the phox domain of Nischarin is sufficient for the interaction with GLT-1. In parallel experiments, coimmunoprecipitation assays in brain lysates generated from adult wild-type (WT) and GLT-1 knockout $\left(\mathrm{GLT}^{\mathrm{KO}}\right)$ animals confirmed the interaction between Nischarin and GLT-1 protein in WT mice, which was lacking in the GLT ${ }^{\mathrm{KO}}$ mice (Fig. 1B). Western blotting in cortical astrocytes derived from rat pups (P0-P2) confirmed expression of endogenous Nischarin (Suppl. Fig.1A).

Using a GST fusion assay, we further narrowed down the binding region within the N-terminal tail of GLT-1 participating in the interaction with Nischarin. The following GST tagged fusion proteins were used as bait; 1) full length GLT-1 N-terminus fusion protein, 2) fusion proteins containing overlapping stretches (15 amino acid in length) of the GLT-1 N-terminus (A-E), 3) full length GLT-C-terminus, and 4) full length GLAST C-terminus, to assess pull down of Nischarin from lysates of GFP-Nisch or GFP transfected COS cells. While the N-terminus of GLT-1 successfully interacted with Nischarin, its C-terminal end and that of GLAST did not. 
Interestingly, within the GLT N-terminal, two 15 amino acid stretches from 9-24 and 23-37 successfully interacted with Nischarin (Fig. 1C). Given that the other GST fused GLT-1 N terminal segments did not interact with Nischarin, this implies that the Nischarin binding site on GLT-1 is complex and that the two sites (9-24 and 23-27) are sufficient for binding Nischarin, independently.

\section{Nischarin promotes endocytosis and not recycling of GLT-1}

Nischarin has been shown to alter the surface levels of receptors, including integrins and mu opioid receptors (Li et al., 2019, Li et al., 2016, Lim and Hong, 2004). To determine whether Nischarin regulated GLT-1 surface density, we used an 'antibody feeding' immunofluorescence internalization assay in HeLa cells to visualize GLT-1 trafficking. HeLa cells were cotransfected with GLT-1 tagged in its extracellular domain with HA (GLT-1a-HA) along with either GFP-Nisch or GFP as a control. Briefly, antibody against the HA tag, present in the extracellular loop of GLT-1, was incubated with the cells for 15 min prior to placing them in the incubator at $37^{\circ} \mathrm{C}$ for $60 \mathrm{~min}$ to allow for internalization, followed by differential immunostaining of the surface and internal GLT-1 pool. To obtain a reference value for basal surface GLT-1 levels prior to internalization, cells were fixed immediately after the antibody surface labelling (constituting the $\mathrm{T}_{0 \min }$ population). At baseline $\left(\mathrm{T}_{0 \mathrm{~min}}\right)$, in control cells, robust surface and low internal GLT-1 labeling was observed. Even after $60 \mathrm{~min}$, a significant change in GLT-1 internalization was not observed in the control (Fig. 2A, 2C), suggesting stable turnover of the transporter under basal culture conditions. In GFP-Nisch expressing cells, although no significant difference was observed in GLT-1 distribution initially at $\mathrm{T}_{0 \mathrm{~min}}$, by 60 min significant increases were observed in the accumulation of GLT-1 within intracellular compartments. (Fig. 2B, 2C). This suggests that Nischarin regulates constitutive trafficking of GLT-1 under basal conditions.

As trafficking of GLT-1 is dependent on endocytic and recycling pathways, we next assessed the effects of Nischarin on GLT-1 recycling. No significant differences were found between the GLT-1 recycling rates in GFP-Nisch cells and control (Supp. Fig. 1B-D). Together, these data suggest that Nischarin promotes translocation of GLT-1 from the surface to intracellular compartments, but (in contrast to its effect on mu opioid receptors: Li et al., 2016) does not affect GLT-1 recycling.

Next, astrocytes were transfected with either GFP-Nisch or GFP-Nisch $\Delta$ phox or GFP control, and co-cultured with hippocampal neurons. At DIV 14, immunostaining studies revealed 
significant co-localization between GFP-Nisch positive endosomal structures and the early endosomal marker EEA1. The GFP-Nisch positive vesicles showed variability in size and shape and were distributed throughout the astrocyte cell body and processes. However, GFP$\Delta$ phox overexpressing cells showed a cytosolic expression of GFP- $\Delta$ phox, corroborating previous reports that Nischarin is targeted to endosomes via its phox domain (Suppl Fig. 2AD). Furthermore, endogenous GLT-1 co-localized significantly with intracellular vesicles positive for GFP-Nisch (Fig 2E). Together these data suggest that intracellular GLT-1 accumulates in Nischarin positive early endosomal structures within the astrocyte cell body and processes.

\section{Glutamate promotes Nischarin mediated GLT-1 intracellular trafficking in fixed and live hippocampal astrocyte cultures.}

It has been previously reported that glutamate treatment decreases clustering and surface expression of GLT-1 (Al Awabdh et al., 2016, Underhill et al., 2015). The PDZ binding domain containing protein DLG1 interacts with the C-terminal PDZ ligand of GLT-1b to regulate its surface density (Underhill et al., 2015). However, the role of molecules interacting with the $\mathrm{N}$ terminus of GLT-1, remains under explored. We therefore investigated whether Nischarin regulates GLT-1 trafficking under activity driven conditions, which we mimicked by applying glutamate.

Using a surface biotinylation assay, the effect of glutamate on surface GLT-1 levels in Nischarin overexpressing astrocytes was assessed. Pure cortical astrocyte cultures were cotransfected with GFP and GLT-1a tagged with V5 (control) or GFP-Nisch and GLT-1a-V5. The transfected cultures were either left untreated or exposed to glutamate $(100 \mu \mathrm{M}, 1 \mathrm{~h})$. Glutamate treatment significantly decreased surface GLT-1 level compared to the untreated control (Fig. 3A), as expected (Ibanez et al., 2016). Nischarin overexpression significantly decreased the GLT-1 surface levels compared to the untreated control in the absence of glutamate, corroborating our findings in Fig. 2. Glutamate treatment in Nischarin overexpressing astrocytes did not cause a further decrease in surface GLT-1 levels in comparison to Nischarin overexpression or glutamate application alone, suggesting that overexpression of Nischarin alone is sufficient to drive the internalisation of surface GLT-1.

Next, using a proximity ligation assay (PLA), a powerful tool that detects a positive protein interaction only if the two proteins are closer than $40 \mathrm{~nm}$, we determined the effect of glutamate 
on the endogenous GLT-1-Nischarin interaction. In DIV14 hippocampal cultures, under control conditions, a significant increase in Nischarin-GLT-1 association (assessed by number of red puncta per DAPI labelled (blue) nuclei) was observed compared to single antibody (Nisch/GLT-1) controls. Upon glutamate treatment $(100 \mu \mathrm{M}, 1 \mathrm{~h})$, the number of puncta observed were significantly increased compared to the control (Fig. 3B). Together with the biotinylation assay, these results suggest that glutamate enhances the endogenous GLT-1Nischarin interaction, and that this drives internalization of surface GLT-1.

To monitor live trafficking of GLT-1, we took advantage of a high affinity 13 amino acid $\alpha$ bungarotoxin (BTX)-binding site (BBS) that has been exploited for tracking AMPA receptor movements in and out of the cell membrane (Sekine-Aizawa and Huganir, 2004). We explored a similar strategy to assess the time course of glutamate's action on the GLT-1-Nischarin interaction, by engineering the extracellular loop of the GLT-1 transporter (Fig. 3C) to include the BBS tag. This position in GLT-1 transporters is silent in terms of its impact on receptor structure and function (Peacey et al., 2009). The astrocytes were co-transfected with GLT-1aBBS and GFP-Nisch and co-cultured with hippocampal neurons. The hippocampal co-culture was incubated with Alexa-555-conjugated BTX (BTX555) at $37^{\circ} \mathrm{C}$ for 20 min to allow live labelling of surface GLT-1. Live time lapse imaging using structured-illumination microscopy (SIM) tracked transporter internalization and individual endosomal events in labelled GLT-1aBBS astrocytes (co-cultured with hippocampal neurons) co-expressing GFP-Nisch and exposed to ACSF alone or ACSF containing 100 $\mu \mathrm{M}$ glutamate (Fig. 3C). GFP-Nisch positive intracellular vesicles were observed within the astrocyte processes and cell body. Glutamate application resulted in internalization of BTX555 labelled surface GLT-1 transporters to GFPNisch labeled vesicles, as seen by the diagonal and colocalized lines in the kymographs representing GLT-1 and Nischarin vesicle movements within the astrocyte process (Fig. 3C). GFP-Nisch was found to be associated with the inner plasma membrane, and the internalized surface GLT-1 was trafficked into GFP-Nisch-positive vesicles, pinched off from the plasma membrane (Suppl. Video 1, 2).

Using the same setup as described above, the co-cultures were exposed to varying durations $(5,30$, or $60 \mathrm{~min})$ of glutamate $(100$ or $0 \mu \mathrm{M})$ and subsequently fixed and imaged using confocal microscopy to ascertain the time course of Nischarin mediated GLT-1 trafficking. GLT-1 showed increased colocalization with GFP-Nisch labeled vesicles (in white, Suppl. Fig. 3A) upon glutamate treatment in comparison to control at all 3 time points (Fig. 3D). Together, 
these results reinforce the role of Nischarin in regulating GLT-1 internalization during glutamate application, with colocalization observed as early as 5 min.

\section{GLT-1 transporter density and function are altered in $\mathrm{Nisch}^{\mathrm{KO}}$ mice}

We further characterized the role of Nischarin mediated regulation of astrocytic GLT-1 by using transgenic Nisch ${ }^{\mathrm{KO}}$ mice (Suppl. Fig. 3B-D). Lack of Nischarin expression was confirmed in homozygous Nisch ${ }^{\mathrm{KO}}$ mice, whereas the heterozygous (Nisch ${ }^{\mathrm{HET}}$ ) mice showed reduced Nischarin protein expression in comparison to the WT control (Fig. 4A). A surface biotinylation assay revealed significant increases in surface GLT-1 levels in astrocytes derived from Nisch ${ }^{\mathrm{KO}}$ transgenic mice compared to from WT control mice. The surface GLT-1 level in astrocytes derived from Nisch ${ }^{\mathrm{HET}}$ transgenics were not significantly different from that of WT (Fig. 4A). Immunostaining studies also revealed a significant increase in total astrocytic GLT-1 mean intensity in hippocampal co-cultures derived from $\mathrm{Nisch}^{\mathrm{KO}}$ mice in comparison to WT control (Fig. 4B). These data support Nischarin's role in regulating GLT-1 surface levels.

Given the increased surface GLT-1 level in Nisch ${ }^{\mathrm{KO}}$ astrocytes, we undertook functional studies where glutamate uptake was assessed using whole cell patch-clamp of astrocytes in hippocampal neuron-glial co-cultures (Brew and Attwell, 1987). For each glutamate anion transported into astrocytes by GLT-1, three $\mathrm{Na}^{+}$and one $\mathrm{H}^{+}$are also transported in, and one $\mathrm{K}^{+}$ is exported from the cell (Levy et al., 1998a, Zerangue and Kavanaugh, 1996, Levy et al., 1998b). Thus, two net positive charges are imported per glutamate taken up, and therefore uptake can be measured from the current it produces. Astrocytes were whole cell patch clamped and their identity was confirmed by the following: 1) dye filling (Alexa 488 or 594) to show coupling with other astrocytes (Fig. 4C), 2) their low input resistance (Suppl. Fig. 4A) and 3) their negative resting potential (Suppl. Fig. 4B). The input resistance and resting potential were not significantly affected by knock-out of Nischarin (Suppl. Fig. 4A, B). After applying blockers of action potentials (150 nM TTX), inward rectifying $\mathrm{K}^{+}$channels i.e. the main conductance of astrocytes $\left(200 \mu \mathrm{M} \mathrm{BaCl}_{2}\right)$, and glutamate and GABA receptors (blocked with $10 \mu \mathrm{M}$ NBQX, $50 \mu \mathrm{M}$ D-AP5, $10 \mu \mathrm{M}$ 5,7-dichlorokynurenate, $10 \mu \mathrm{M}$ MK-801 and $10 \mu \mathrm{M}$ bicuculline), once a steady membrane current was reached, at a voltage near the cell's resting potential $(-90 \mathrm{mV})$, glutamate transporters were activated by applying D-aspartate $(200 \mu \mathrm{M})$. D-aspartate evoked an inward current in both WT and $\mathrm{Nisch}^{\mathrm{KO}}$ astrocytes (Fig. 4E). The currents were confirmed to be mediated by glutamate transporters, since they were blocked by 
the GLT-1 and GLAST blocker TFB-TBOA (10 $\mu$ M Fig. 4D, F). Consistent with the surface biotinylation assay, we found that the glutamate uptake current was almost two-fold higher in the $\mathrm{Nisch}^{\mathrm{KO}}$ astrocytes in comparison to the WT astrocytes ( $p=0.029$, Fig. 4E, F).

Dysfunction of glutamate clearance can cause overstimulation of glutamate receptors and result in neuronal injury, termed excitotoxicity. To further investigate the neuroprotective function of astrocytes, we carried out an excitotoxicity assay using hippocampal neuron -astrocyte cocultures derived from WT and Nisch ${ }^{\mathrm{KO}}$ mice (at DIV 14). The cultures were challenged with $10 \mu \mathrm{M}$ glutamate and $10 \mu \mathrm{M}$ glycine for 24 hours. Neuronal death was analyzed using propidium iodide (PI) and DAPI staining, and the number of PI-positive nuclei (red) were counted. Glutamate treatment evoked significantly less PI-labelling of neurons in $\mathrm{Nisch}^{\mathrm{KO}}$ cocultures compared with neurons in wild type co-cultures (Fig. 4G). These data suggest that when challenged with neurotoxic glutamate levels, lack of Nischarin is protective against cell death, presumably due to the increased glutamate uptake that lack of Nischarin results in.

\section{Discussion}

Glutamatergic neurons are responsible for majority of the excitatory synaptic transmission and plasticity occurring in the brain. The astrocytic glutamate transporters serve the critical role of efficiently clearing glutamate from the extracellular space (Tanaka et al., 1997) to ensure normal glutamate signalling. GLT-1 is one of the highest expressed proteins in the brain (1\% of total brain protein: (Lehre and Danbolt, 1998). The high number of surface glutamate transporters (GLT-1 at a density of 8,500 transporters/ $\mu \mathrm{m} 2$ as well as GLAST at 2,500 transporters $/ \mu \mathrm{m} 2)$ compensate for the slow transport cycle $(12-70 \mathrm{~ms})$ to ensure effective clearance of the $\sim 4000$ glutamate molecules released from a single synaptic vesicle (Lehre and Danbolt, 1998, Murphy-Royal et al., 2017). GLT-1 undergoes activity-dependent surface diffusion, and glutamate-bound GLT-1 from 'synapse facing' sites are continuously replaced with GLT-1 lacking bound glutamate to help maintain a high concentration of available surface transporters at the astrocytic plasma membrane (Murphy-Royal et al., 2017). Thus, an in-depth understanding of the molecular mechanisms regulating and maintaining the surface GLT-1 density is crucial. Here, we have identified a novel interacting protein partner, Nischarin, a non-adrenergic imidazoline-1 receptor (Alahari, 2003) that regulates intracellular trafficking of GLT-1 in response to the neurotransmitter glutamate. 
We found that Nischarin interacts with the N-terminal tail of GLT-1 through its phox domain. Specifically, Nischarin co-precipitated with amino acids 9-37 within the intracellular, unstructured N-terminal tail of GLT-1. Amino acids 9-23 have also been implicated in the interaction with Ajuba, a scaffolding protein that allows GLT-1 to regulate intracellular signalling or interact with the cytoskeleton (Marie et al., 2002). These amino acids are conserved across the four GLT-1 isoforms (Peacey et al., 2009), suggesting Nischarin could regulate all four isoforms, unlike previously identified regulators of GLT-1 trafficking that bind specifically to the PDZ domain found in GLT-1b (Bassan et al., 2008, Underhill et al., 2015). Additionally, a co-immunoprecipitation assay using brain lysates confirmed that the NischarinGLT-1 interaction occurs in intact brain. The findings reported here raise the intriguing possibility that, in addition to Nischarin's previously reported role in regulating cytoskeletal signalling, cell migration, Rab-dependent endosomal sorting, and regulation of integrins and mu opioid receptors (Keller et al., 2017, Kuijl et al., 2013, Alahari, 2003), it may have an activity-dependent role in modulating glutamate concentration at the synapse.

GLT-1 is known to undergo constitutive and regulated endocytosis, which determines its availability for glutamate clearance from extracellular compartments in the nervous system (Martinez-Villarreal et al., 2012). Our antibody feeding assays have revealed that overexpression of Nischarin redistributed surface GLT-1 transporters into endosomal structures, but did not alter transporter recycling under basal conditions. Taken together, our data not only support an interaction between Nischarin and GLT-1 but also indicate the possibility that Nischarin alters trafficking of GLT-1 by sequestration. The phox domain of Nischarin is a stretch of $\sim 110$ amino acids that is a phosphatidylinositol 3-phosphate-binding (PI3P) module, and PI3P is enriched in early endosomal membranes (Lim and Hong, 2004). Our data confirmed previous findings that Nischarin is targeted to early endosomes, marked by EEA1 (Kuijl et al., 2013), but also showed multiple Nischarin positive yet EEA1 negative vesicular structures, revealing a much wider distribution of Nischarin within the endosomal system. Furthermore, we observed that the GLT-1-Nischarin vesicular structures are spatially distributed along the astrocyte cell body and processes.

Surface biotinylation studies revealed that astrocytic GLT-1 surface levels decreased (40\%) in response to glutamate (Fig. 3A), which is consistent with previous findings (Ibanez et al., 2016). Overexpressing Nischarin in astrocytes exposed to glutamate treatment did not significantly further alter surface GLT-1 levels, implying that Nischarin occludes the effect of glutamate on surface GLT-1. Alteration in surface GLT-1 levels by Nischarin could offer a 
means for modulating glutamatergic activity at the synapse. Given the increased Nisch-GLT-1 interaction following glutamate exposure, a likely explanation for these results is that Nischarin mediates the effects of glutamate dependent GLT-1 surface density regulation. The recruitment of Nischarin to GLT-1 could have additional consequences as Nischarin is known to act as a scaffolding platform for signalling pathways through its interactions with multiple proteins including, integrin $\alpha 5$, PAK, Rac, LIMK and ERK (Alahari, 2003, Alahari et al., 2000, Juliano et al., 2004). Further work is also needed to establish whether the blood pressure lowering effects of imidazoline drugs such as clonidine are in any way mediated by effects on glutamate transport.

Using time-lapse monitoring of the transporter (employing a GLT-1aBBS construct that can bind fluorophore conjugated BTX, eliminating the use of bulky antibodies which could promote clustering and affect membrane trafficking properties (Sekine-Aizawa and Huganir, 2004) we showed that glutamate binding and/or transport triggered intracellular trafficking of GLT-1 into Nischarin labelled intracellular compartments within 5 min of glutamate exposure. This time course suggests that the GLT-1-Nisch trafficking could be of more relevance in pathological conditions such as ischemia or traumatic brain injury, where the extracellular concentration of glutamate remains elevated (in the 100-200 $\mu \mathrm{M}$ range) for hours (Ibanez et al., 2016). SIM resolution allowed tracking of single GFP-Nisch labelled vesicles containing GLT-1BBS bound BTX555, and the resultant kymograph confirmed co-localization and inwardly directed (towards the cell body), slow ( minutes) movement as vesicles traversed the astrocytic process.

Astrocytes derived from Nisch ${ }^{\mathrm{KO}}$ transgenic animals exhibit increased surface GLT-1 density and a concomitant two-fold increase in transporter uptake currents. This enhanced surface GLT-1 density served to reduce cell death after glutamate insult, demonstrating the relevance of this mechanism to pathology. Dysregulation of Nischarin regulation of GLT-1 transporter surface density and function could affect glutamate clearance. Ineffective glutamate clearance is observed in many neurodegenerative diseases, including amyotrophic lateral sclerosis, epilepsy, Alzheimer's, Huntington's and Parkinson's disease (Hindeya Gebreyesus and Gebrehiwot Gebremichael, 2020, Peterson and Binder, 2019). Together, this work not only reveals a novel mechanism by which GLT-1 intracellular trafficking and function are regulated but also provides possible new avenues of research for treating neurological disorders. 


\section{Acknowledgements}

This work was supported by grants from the BBSRC (BB/I00274X/1) and European Research Council grant 282430 (Fuelling Synapses) to J.T.K. S.M. was supported by an EMBO LongTerm Fellowship and Marie Skłodowska-Curie International Incoming Fellowship (Nos. 630033 and 913033). This work was also supported by a PhD studentship from the Medical Research Council (MRC) to J.D. (1477260) and a Wellcome Trust 4 year PhD studentship in Neuroscience to N.B. D.A. was supported by an Investigator Award (099222/Z/12/Z) from the Wellcome Trust. We thank all members of the Kittler laboratory for helpful discussions and comments. We also thank the Light Microscopy facility at the MRC Laboratory for Molecular Cell Biology SURF facility for training and technical support. 


\section{Figure Legends}

Figure 1: The phox domain of Nischarin interacts with GLT-1.

A) Schematic diagram depicting full length Nischarin and GFP-tagged mutants. GLT-1aV5 coimmunoprecipitated with GFP-phox and not GFP-Nisch $\Delta$ phox mutant or GFP control.

B) Coimmunoprecipitation experiments from mouse brain homogenate from WT and GLT ${ }^{\mathrm{KO}}$ mice, showing Nischarin to be part of a native complex with GLT-1 $(n=3)$.

C) Schematic diagram of GST fusion constructs for GLT-1 N-terminus, 15 amino acid stretches of GLT-1 N-terminus (A-E), GLT-1 C-terminus and GLAST C-terminus. GFP-Nisch was successfully pulled down with full length GST fused GLT-1 N-terminus and to GST fusions D (amino acids 9-23) and E (amino acids 23-37).

Figure 2: Antibody feeding assay revealed that Nischarin promotes internalization of GLT-1.

Surface and internal GLT-1 populations labelled in HeLa cells co-expressing A) GFP and GLT1a-HA or B) GFP-Nisch and GLT-1a-HA at 0min and 60min.

C) Quantification of internalized GLT-1 to total GLT-1 levels at $\mathrm{T}_{60}$ min relative to $\mathrm{T}_{0 \mathrm{~min}}$. Oneway ANOVA, Kruskal-Wallis test with Dunn's correction $(n=12)$.

Figure 3: Nischarin mediates glutamate-dependent GLT-1 internalization in astrocytes.

A) Surface biotinylation assay showing surface GLT-1 level in astrocytes transfected with GFP and GLT-1a-V5 or GFP-Nisch and GLT-1a-V5 following +/- 100 $\mu \mathrm{M}$ glutamate treatment. One-way ANOVA, post hoc Dunnett's multiple comparison test $(n=4$ individual experiments).

B) Proximity ligation assay in DIV14 hippocampal culture. Increased red puncta per nuclei (DAPI stained (blue)) is indicative of increased direct interaction between Nischarin and GLT1 in hippocampal culture. Glutamate treatment $(100 \mu \mathrm{M}, 1 \mathrm{~h})$ significantly increased GLT-1Nischarin interaction compared to control. One-way ANOVA, post hoc Tukey's test $(\mathrm{n}=3$ individual preparations).

C) Schematic representation of GLT-1BBS construct bound to BTX conjugated Alexa-555 (BTX555). Astrocytes expressing GFP-Nisch and GLT-1aBBS were labelled using BTX555 and dual colour live structured illumination microscopy monitored trafficking of GLT-1 
following glutamate treatment. Merged kymographs of GFP-Nisch vesicle (green) and GLT-1 bound BTX-555 (red) reveal co-localized diagonal trajectory, representing moving vesicles.

D) Quantification of GFP-Nisch and GLT-1aBBS expressing astrocytes treated with $100 \mu \mathrm{M}$ glutamate for $0,5,30$ and $60 \mathrm{~min}$ showed increased co-localization between Nisch and GLT-1 compared to untreated controls. P values by unpaired t-test, Mann Whitney test $(n=6-14)$.

Figure 4: GLT-1 surface density and transporter uptake current are enhanced in $\mathrm{Nisch}^{\mathrm{KO}}$ astrocytes.

A) Western blot analysis in cortical astrocytes derived from WT, Nisch ${ }^{\mathrm{HET}}$ and $\mathrm{Nisch}^{\mathrm{KO}} \mathrm{E} 16$ embryos, confirmed decrease and loss of Nischarin in the HET and KO cultures. Surface biotinylation assay showed significant increase in GLT-1 surface density in KO culture compared to WT control. One-way ANOVA, post hoc Tukey's test ( $n=3$ animals).

B) Representative images for GLT-1 (green) and Map2 (red) immunostaining in astrocytes derived from DIV14 WT and Nisch ${ }^{\mathrm{KO}}$ hippocampal culture. A significant increase in GLT-1 mean fluorescence intensity was observed in $\mathrm{Nisch}^{\mathrm{KO}}$ astrocytes. Unpaired Student t-test $(n=$ 11-13).

C) Examples of astrocytes filled with Alexa 488 from the patch pipette (still attached to the cell for the WT and after electrode removal for the $\mathrm{Nisch}^{\mathrm{KO}}$ ) in WT and $\mathrm{Nisch}^{\mathrm{KO}}$ hippocampal tissue cultures.

D) The D-aspartate evoked current is completely blocked by TFB-TBOA.

E) A significantly larger D-aspartate evoked current was recorded in the $\mathrm{Nisch}^{\mathrm{KO}}$ astrocytes compared to the WT, unpaired student t-tests.

F) Sample traces showing the D-aspartate evoked $(200 \mu \mathrm{M})$ current and its inhibition by the GLT-1 and GLAST transporter blocker TFB-TBOA (TFB, $10 \mu \mathrm{M})$, in WT and $\mathrm{Nisch}^{\mathrm{KO}}$ astrocytes.

G) Representative confocal images showing nuclear staining DAPI (cyan) and PI labelling (red) in DIV 14 WT and Nisch ${ }^{\mathrm{KO}}$ hippocampal culture, 24h following a glutamate insult. Bar graph showing percentage of PI-labelled nuclei ( $n=3$, unpaired two-tailed t-test). 
Suppl. Movies 1 and 2.: Single internalization events showing inward movement of GFPNisch positive intracellular vesicle (green) and GLT-1-BBS-BTX555 (red) captured using time lapse confocal microscopy under basal conditions and following glutamate treatment (100 $\mu \mathrm{M})$. Images were acquired every $20 \mathrm{sec}$; movie accelerated to $10 \mathrm{fps}$. Scale bar $5 \mu \mathrm{m}$.

\section{Suppl. Figure 1:}

A) Representative western blots for endogenous Nischarin present in cortical neuron culture and pure astrocytic culture.

Nischarin does not affect GLT-1 recycling. HeLa cells co-expressing B) GFP and GLT-1a-HA or C) GFP-Nisch and GLT-1a-HA were live-labelled with anti-HA and rate of recycling was assayed using antibody feeding. D) No difference in recycled GLT-1 levels was observed in the two groups at $\mathrm{T}_{30 \mathrm{~min}}$ and $\mathrm{T}_{60 \mathrm{~min}}$. At $\mathrm{T}_{60 \mathrm{~min}}$, both GFP control and GFP-Nisch overexpressing cells showed significant recycling of GLT-1 to the surface compared to $\mathrm{T}_{0}$ min, One-way ANOVA, post hoc Tukey's test $(n=12)$.

Suppl. Figure 2: Structured illumination microscopy showing A) GFP-Nisch or B) GFPNisch $\triangle$ phox or C) GFP and endogenous GLT-1 (red) and EEA1 (magenta) in astrocytes of DIV14 hippocampal culture.

D) Significant colocalization was observed between GFP-Nisch and the endogenous endosomal marker, EEA1 in comparison to the GFP-Nisch $\Delta$ phox mutant and GFP control. One-way ANOVA, Kruskal Wallis test with Dunn's multiple comparison test ( $n=18-24$ cells).

E) Significant colocalization was observed between GFP-Nisch and endogenous GLT-1 in comparison to GFP-Nisch $\Delta$ phox mutant and GFP control. One-way ANOVA, post hoc Tukey's test ( $n=15-20$ cells). 


\section{Suppl. Figure 3:}

A) Confocal images of GFP-Nisch and GLT-1aBBS expressing astrocytes treated with $100 \mu \mathrm{M}$ glutamate for $0,5,30$ and 60 min showed increased co-localization (shown in white) between GFP-Nisch (green) and GLT-1 compared to untreated controls.

B) The Nisch transgenic line was generated following the knockout-First strategy applied to the C57BL/6N Taconic strain. A L1L2_Bact_P cassette encoding an engrailed1 splice acceptor sequence, a LacZ reporter and a neomycin resistance gene was inserted between exons 4 and 5, disrupting Nisch transcription.

C) Xgal staining (dark blue) of sagittal brain section of a Nisch ${ }^{\mathrm{HET}}$ animal demonstrates widespread Nischarin expression throughout the brain. Inset, hippocampus shows enriched Nischarin expression.

D) PCR analysis on DNA extracted from E16 WT, Nisch ${ }^{\mathrm{KO}}$ and $\mathrm{Nisch}^{\mathrm{HET}}$ embryos shows successful recognition of the WT and Nisch deletion alleles.

\section{Suppl. Figure 4:}

A \& B) Astrocytes from WT and $\mathrm{Nisch}^{\mathrm{KO}}$ hippocampal tissue cultures showed a similar membrane resistance (A), and resting potential $(\mathbf{B})$. 


\section{Materials and Methods}

\section{Transgenic Animal}

The Nisch (HEPD0811_2_A03; Allele: Nisch ${ }^{\text {tmla(EUCOMM)Hmgu }}$ ) mouse line was obtained from the Wellcome Trust Sanger Institute as part of the International Knockout Mouse Consortium (IKMC) (Skarnes et al., 2011). The Nisch transgenic line was generated following the Knockout-First strategy on C57BL/6N Taconic strain. A L1L2_Bact_P cassette encoding an engrailed1 splice acceptor sequence, a LacZ reporter and a Neomycin resistance gene was inserted between exons 4 and 5 disrupting Nisch transcription. Animals were maintained under controlled conditions (temperature $20 \pm 2{ }^{\circ} \mathrm{C} ; 12$ hour light-dark cycle). Food and water were provided ad libitum. The genotyping was carried out following Sanger's recommended procedures, briefly the DNA was extracted from ear biopsies and PCRs were performed with the following primers (5' to 3 '): Nisch_5arm_WTF: AGAGGCCCAGAGACCTGATA; Nisch_Crit_WTR: TGGACACGTGATGAGAAAGG; 5mut_R1: GAACTTCGGAATAGGAACTTCG; LacZ_2_small_F: ATCACGACGCGCTGTATC; LacZ_2_small_R: ACATCGGGCAAATAATATCG. All experimental procedures were carried out in accordance with institutional animal welfare guidelines and licensed by the UK Home Office in accordance with the Animals (Scientific Procedures) Act 1986.

\section{Yeast two-hybrid screen.}

This screen was done as described previously (Marie et al., 2002). Briefly, bait cDNA for the GLT-1 $\mathrm{N}$ terminus (amino acids $1-44$ of the rat protein sequence) was cloned into the yeast expression vector pPC97 in frame with the GAL4 binding domain. It was screened against a random-primed cDNA library from seizure-stimulated adult rat hippocampus cloned in the yeast expression vector pPC86 in frame with the GAL4 activation domain. Interacting proteins were identified by colony selection on plates lacking leucine, tryptophan, and histidine and confirmed by using a $\beta$-galactosidase assay and by checking that in the absence of GLT-1 bait the library protein did not activate the reporter genes (His3, allowing growth on histidinedeficient medium, and $L a c Z$, expressing $\beta$-galactosidase).

\section{Plasmid constructs}

Mouse GLT-1a cDNA with V5 and HA epitope tag inserted into the extracellular loop of the transporter (between Pro ${ }^{199}$ and Pro ${ }^{200}$ ) and cloned into pcDNA3.1- was gifted by Dr. M. 
Rattray (Peacey et al., 2009). Bungarotoxin binding sequence (BBS) tag was introduced by PCR into GLT-1a and 1b between the two proline residues (P199 and P200) in the extracellular loop using the following primers (written 5 , to 3 '): ccetggagccetaccetgacCCATCTGAGGAGGCC;

agctctcgtagtatctccaaGGTGCCACCAGAACTTT, where lowercase text corresponds to the sequence of the BBS tag. Mouse Nischarin vector (clone ID: 100068156) was obtained from I.M.A.G.E. Consortium. The phox domain of Nischarin was deleted using the following primers: GTAAATGGTGTCACTGCAGCACT, CTCAGGGCCGAAGCTGAGTGT. The dominant negative, phox vector was generated using the following primers: GgCCtCAtGgGCCCAG, ttcatagaggtgaAaAtgcagga. The full length Nischarin, Dphox and phox vectors were C-terminally tagged with GFP by infusion cloning in frame into CAG-GFP (Addgene) using the following primers: ATCATTTTGGCAAAGCTAGCaccatggeggetgcgacact and CGTCGACTGCAGAATTCtgccagtgagctccacaggc, where lowercase text corresponds to parts of the Nischarin sequence. Neuronal processes were targeted using the RGECO vector obtained from Addgene.

\section{Preparation and transfection of astrocyte cultures}

Primary cultures of cortical astrocytes were prepared from E18 or P0 Sprague-Dawley rats as previously described (Banker G, 1998). Cells were maintained in Dulbecco's modified Eagle's medium DMEM GlutaMAX (Invitrogen) supplemented with $4.5 \mathrm{~g} / \mathrm{L}$ glucose, $20 \%$ fetal bovine serum, $10 \mathrm{u} / \mathrm{ml}$ penicillinG, and $100 \mu \mathrm{g} / \mathrm{ml}$ streptomycin at $37^{\circ} \mathrm{C}$ with $5 \% \mathrm{CO} 2$ in a humidified incubator. Media was exchanged the day after plating. Astrocytes were passaged when confluency was reached (10 days after plating). For biotinylation assay, astrocytes were transfected with GLT-1aV5 and GFP $(2 \mu \mathrm{g}, 1 \mu \mathrm{g})$ or GLT-1aV5 and GFP-Nisch $(2 \mu \mathrm{g}, 2 \mu \mathrm{g})$ using Amaxa Nucleofector ${ }^{\circledR}$ technology following the manufacturer's protocol and maintained for 5 to 7 days before processing.

\section{Preparation and transfection of mixed culture and the neuron-astrocyte co-cultures}

Hippocampal cultures were obtained from E18 rat embryos as described previously with some modifications (Arancibia-Carcamo et al., 2009). In order to enrich the culture with astrocytes, the neurons were kept $24 \mathrm{~h}$ after plating in attachment medium (Minimal Essential Medium, 10\% Horse Serum, $1 \mathrm{mM}$ Sodium Pyruvate and 0.6\% Glucose) before replacing with maintenance medium (Neurobasal Medium, B27 supplement, Glutamax, 0.6\% Glucose, 
Penstrep). For optosplit experiments, after transfecting DIV7 hippocampal neurons with RGECO (lipofectamine 2000), astrocytes were transfected by nucleofection with GFP-Nisch $(2 \mu \mathrm{g})$ or GFP $(1 \mu \mathrm{g})$ (Amaxa Nucleofector) and plated on top of the RGECO transfected neurons. Transfected astrocytes were maintained with neurons for 3 to 4 days before multiwavelength live-imaging. For live and fixed time lapse confocal and SIM imaging, astrocytes were transfected by nucleofection with GLT-1aBBS and GFP-Nisch $(2 \mu \mathrm{g}, 2 \mu \mathrm{g})$ or GLT1aBBS and GFP $(2 \mu \mathrm{g}, 1 \mu \mathrm{g})$ (Amaxa Nucleofector) and plated on top of DIV10 hippocampal neurons. Transfected astrocytes were maintained with neurons for 3 to 4 days before imaging.

\section{Cell culture and transfection}

COS7 and HeLa cells were maintained in $10 \mathrm{~cm}$ dishes containing $10 \mathrm{ml}$ Enhanced Dulbecco's Modified Eagles Medium (DMEM), supplemented with pen/strep and $10 \% \mathrm{FBS}$, at $37^{\circ} \mathrm{C}$ and $5 \% \mathrm{CO} 2$, transfected by nucleofection using an Amaxa electroporator and allowed 24-48 hours for protein expression.

\section{Coimmunoprecipitation assays from rat brain homogenate and cell culture}

Coimmunoprecipitation experiments from brain/cell culture were performed as previously described (Twelvetrees et al., 2010). Briefly, mouse brain/cell culture expressing proteins of interest was homogenised in pull- down buffer (50 mM TRIS pH 7.5, 0.5\% triton X-100, 150 $\mathrm{mM} \mathrm{NaCl}, 1 \mathrm{mM}$ EDTA, $1 \mathrm{mM}$ PMSF with antipain, pepstatin and leupeptin at $10 \mu \mathrm{g} / \mathrm{ml}$ ) and solubilised for 2 hours. Solubilised material was ultracentrifuged at $66,000 \mathrm{~g}$ for 40 minutes at $4^{\circ} \mathrm{C}$ and the supernatant (solubilised protein) was incubated with $2 \mu \mathrm{g}$ of anti-GLT1 (Alomone, Cat No: AGC022) antibody overnight at $4^{\circ} \mathrm{C}$. To precipitate complexes, $20 \mu$ protein-A or $-\mathrm{G}$ beads or GFP trap beads (Chrometek) were added for 1 hour at $4{ }^{\circ} \mathrm{C}$. Beads were then washed extensively and bound complexes were analysed by SDS-PAGE and western blotting.

\section{Western Blotting}

SDS - polyacrylamide gel electrophoresis (PAGE) and Western Blotting samples were denatured at $94^{\circ} \mathrm{C}$ for 5 minutes in $3 \mathrm{x}$ SDS sample buffer $(150 \mathrm{mM}$ Tris $\mathrm{pH} 8,6 \%$ SDS, $0.3 \mathrm{M}$ DTT, 0.3\% Bromophenol Blue, 30\% glycerol). Polyacrylamide gels were prepared using 10\% running gels and 5\% stacking gels in Novex $1.5 \mathrm{~mm}$ Cassettes and run using the Novex XCell SureLock Mini-Cell system. Gels were transferred onto Hybond-C nitrocellulose membrane (GE Healthcare). Membranes were blocked in 4\% milk for 1 hour and incubated overnight at 
$4^{\circ} \mathrm{C}$ with shaking in the appropriate primary antibody against Nischarin (1:500, BD Biosciences, Cat No: 558262), GFP (1:500, Santacruz, Cat No: sc-8334), V5 (1:2000, Invitrogen, Cat. No: R960-25), GLT (1:500, Alomone). HRP-conjugated secondary antibodies were from Rockland (1:10,000). Bands were visualised using Crescendo Chemiluminescent substrate (Millipore) together with an ImageQuant LAS 4000 CCD camera system (GE Healthcare).

\section{GST pull down assays from transfected COS7 cells}

GST fusion with amino acids $1-44$ of the N terminus of GLT-1 (GST-GLT-N), C terminus of GLT-1 (GST-GLT-C) and C terminus of GLAST (GST-GLAST-C), GST fusions A-E, encoding amino acids 1-15, 15-30, 30-44, 9-23, and 23-37 of GLT-1 were cloned as described previously (Marie et al., 2002). Pull-downs from brain were performed as described previously (Smith et al., 2008, 2010). Briefly, COS cells transfected with GFP-Nisch $(2 \mu \mathrm{g})$ was homogenized in pull-down buffer (50 mM HEPES, $\mathrm{pH}$ 7.5, 0.5\% Triton X-100, $150 \mathrm{mM}$ $\mathrm{NaCl}, 1 \mathrm{mM}$ EDTA, and $1 \mathrm{mM}$ PMSF with antipain, pepstatin, and leupeptin at $10 \mathrm{~g} / \mathrm{ml}$ ) and solubilized for $2 \mathrm{~h}$. Solubilized material was ultracentrifuged at $66,000 \mathrm{~g}$ for $40 \mathrm{~min}$ at $4{ }^{\circ} \mathrm{C}$, and

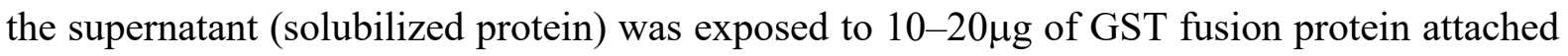
to glutathione-agarose beads for $1 \mathrm{hr}$ at $4^{\circ} \mathrm{C}$. Beads were then washed extensively and analyzed by SDS-PAGE and western blotting.

\section{Biotinylation Assay}

Surface biotinylation assays have been fully described previously (Smith et al., 2010; Twelvetrees et al., 2010). Briefly confluent astrocyte cultures were incubated on ice with biotin solution (Sulpho-NHS-biotin(PIERCE) at $0.5 \mathrm{mg} / \mathrm{ml}$ in PBS containing $\mathrm{Ca}^{2+} / \mathrm{Mg}^{2+}$ ) and quenched with quench buffer (PBS Ca2+/Mg2+containing $1 \mathrm{mg} / \mathrm{ml} \mathrm{BSA}$ ). Astrocytes were solubilised for 1 hour in RIPA buffer (50 mM Tris pH 7.5, 1mM EDTA, 2 mM EGTA, 150 $\mathrm{mM} \mathrm{NaCl}, 1 \% \mathrm{NP} 40,0.5 \%$ DOC, $0.1 \%$ SDS, and $1 \mathrm{mM}$ PMSF with antipain, pepstatin and leupeptin $10 \mu \mathrm{g} / \mathrm{ml}$ ) and the lysates were then centrifuged to pellet cell debris. $15 \%$ of the supernatant was taken to use as a total protein sample and the remainder was incubated for $2 \mathrm{~h}$ with $25 \mu$ Ultralink immobilized NeutrAvidin (PIERCE) $50 \%$ slurry at $4{ }^{\circ} \mathrm{C}$ to precipitate biotin labeled membrane proteins. Beads were washed three times in RIPA buffer and analysed by SDS-PAGE and western blotting. Biotinylated surface GLT-1 transporters were identified by using anti-GLT primary antibody (1:500, Alomone) or anti-V5 primary antibody $(1: 2000$, 
Invitrogen) and detection of enhanced chemilluminescence from HRP-coupled anti-rabbit secondary antibodies followed by detection with an ImageQuant LAS4000 mini imaging system and analysis with ImageQuant software (GE Healthcare).

\section{Excitotoxicity Assay}

DIV14 hippocampal cultures were treated for 20 minutes with $10 \mu \mathrm{M}$ Glutamate and $10 \mu \mathrm{M}$ Glycine before replacement with conditioned maintenance media. 24 hours later, cultures were treated with $10 \mu \mathrm{g} / \mathrm{mL}$ Propidium Iodide (PI) for 10 minutes prior to fixation for 5 minutes with $4 \%$ PFA at room temperature. Cell nuclei were stained with DAPI. Coverslips were imaged by confocal microscopy using a 10x objective (0.8x digital zoom, 4 averaging, 1024x1024, bit depth 8). Laser power and gain were kept consistent within and across all experiments. Images were analysed using ImageJ Cell Counter plugin, manually counting DAPI+ve cells and PI+ve cells in the same field of view. 3-4 field of views were taken per coverslip, 3-6 coverslips taken per embryo. N=3 litter-matched embryos from separate preps. Experiments were performed blinded during image acquisition and analysis.

\section{Proximity Ligation Assay}

The in-situ proximity ligation assay (PLA) was used according to the manufacturer's instructions (Olink Bioscience). Neurons were fixed in 4\% PFA/30\% sucrose, blocked (10\% horse serum, $0.5 \% \mathrm{BSA}$, and $0.2 \%$ Triton $\mathrm{X}-100,10 \mathrm{~min}$ at room temperature), and incubated with primary antibodies (1:500, anti-GLT (gift from Dr. N.Danbolt) and anti-Nischarin (1:100, Sigma, Cat. No: HPA023189). For control PLA, single primary antibody was applied. Cells were washed in $1 \times$ PBS and then incubated with secondary antibodies conjugated to oligonucleotides. Ligation and amplification reactions were conducted at $37^{\circ} \mathrm{C}$, before mounting and visualization with confocal laser scanning microscope. Images were thresholded and number of puncta and DAPI stained nuclei were manually counted for each image using the Metamorph software. Experiments were performed blinded during image acquisition and analysis.

\section{Antibody Feeding}

For receptor internalization and recycling assays, HeLa cells were transfected with GFPNisch and GLT-1a-HA $(2 \mu \mathrm{g}, 2 \mu \mathrm{g})$ or GFP and GLT-1a-HA $(1 \mu \mathrm{g}, 2 \mu \mathrm{g})$. The transporters were live labeled with anti-HA antibody in DMEM $+25 \mathrm{mM}$ HEPES at $17^{\circ} \mathrm{C}$. Labelled transporters were 
allowed to internalize for $60 \mathrm{~min}$ at $37^{\circ} \mathrm{C}$. For recycling assay, surface transporters were stripped using acid wash $(0.2 \mathrm{M}$ acetic acid and $0.5 \mathrm{M} \mathrm{NaCl})$. Cells were then returned to the incubator for $30 \mathrm{~min}$ and $60 \mathrm{~min}$ at $37^{\circ} \mathrm{C}$ to allow internalized transporters to recycle to the surface. For surface staining, cells were fixed with 4\% paraformaldehyde (PFA)/4\% sucrose/PBS, pH 7, for 5 min and blocked with block solution (PBS, 10\% horse serum, and $0.5 \% \mathrm{BSA}$ ) for $10 \mathrm{~min}$, followed by Alexa Fluor-555-conjugated anti-mouse secondary antibody for $1 \mathrm{hr}$ (1:400; Invitrogen). For identifying internalized transporters, cells were subsequently permeabilized with block solution containing $0.2 \%$ Triton X-100 for $10 \mathrm{~min}$, followed by Alexa Fluor-555-conjugated anti-mouse secondary antibody (1:1000; Invitrogen). After extensive washing, coverslips were mounted on microscope slides using ProLong Gold antifade reagent (Invitrogen) and sealed with nail varnish. Images were attained using the confocal laser scanning microscope. Image analysis was performed using ImageJ software. For quantification of receptor internalization, red fluorescence that was not colocalized with cyan fluorescence (surface receptors) was calculated as the internalized transporter population or vice versa for calculating the surface transporter population in the recycling assay and normalized to total transporter population. Rate of internalization/recycling at different time points is measured as fold change relative to $0 \mathrm{~min}$.

\section{Immunostaining}

Hippocampal cell culture was fixed with $4 \% \mathrm{PFA} / 4 \%$ sucrose/PBS, pH7, for $5 \mathrm{~min}$. The cells were permeabilized with block solution (PBS, $10 \%$ horse serum, and $0.5 \%$ BSA, $0.2 \%$ Triton) for 10min. The cells were incubated with primary antibodies including, anti-GLT1 (1:500, Alomone), anti-EEA1 (1:500, BD Bioscience, Cat. No: 610456), anti-Map2 (1:1000) for 1hr in block solution, followed by incubation with Alexa Fluor-488 or 555 or 647- conjugated secondary antibodies (1:1000, Invitrogen) for $1 \mathrm{hr}$. After extensive washing, coverslips were mounted on microscope slides using ProLong Gold antifade reagent (Invitrogen) and sealed with nail varnish. Images were attained using Zeiss LSM 700 upright confocal microscope with an Apochromat $63 \times$ oil immersion lens with 1.4 numerical aperture. Images were digitally captured using ZEN software with excitation at 488nm for GFP and Alexa-Fluor 488, 555nm for Alexa-Fluor 555 and $633 \mathrm{~nm}$ for Alexa-Fluor 647 and conjugated secondary antibodies. Pinholes were set to 1 Airy unit creating an optical slice of $0.8 \mu \mathrm{m}$. For measuring colocalization, the colocalization plugin of the Metamorph software was used. Fluorescence intensity was measured using the ImageJ software. 


\section{Live Imaging}

Structured Illumination Microscopy was performed using a Zeiss Elyra PS.1 equipped with 488, 555 and $642 \mathrm{~nm}$ lasers. Images were acquired with $63 \times 1.4 \mathrm{NA}$ oil immersion objective using pco.edge sCMOS camera and Zen 2012 image analysis software. Typically, images were acquired with $51 \mu \mathrm{m}$ grating and 3 rotations by exciting fluorophores with $1-3 \%$ laser intensity and 120-150 ms exposure time. Post-acquisition, images were processed with Zen 2012 using the SIM reconstruction module with default settings and drift corrections between the channels were performed with respect to 100nm Tetraspec fluorescent microspheres (Molecular probes). To create kymographs image sequences were opened within ImageJ. Curved processes were straightened using the "straighten" macro and kymographs created by the "multiple kymograph" macro. Resultant kymographs show the process along the x-axis and time across the y-axis.

\section{Multi wavelength imaging and analysis (Optosplit)}

An inverted Zeiss Axiovert 200 microscope (63x 1.4 NA oil objective), attached to an Evolve (EMCCD) camera (Photometrics), fitted with an image splitter (Optosplit II, Cairn Research), allowed simultaneous acquisition of images at two separate emission wavelengths. Videos were recorded at $8.5 \mathrm{~Hz}$ using Micro-manager software (Edelstein et al., 2010). Excitation was achieved through a D470/40X filter (Chroma) and emission was split using a 565DCXR dichroic beam-splitter (Chroma), subsequently collecting with HQ522/40M and HQ607/75M (Cairn Research) filters for GFP and RGECO, respectively. A Grass S9 stimulator and a stimulation bath (Warner Instruments) allowed field stimulation (10 Hz for $10 \mathrm{~s}$ ) of neuronastrocyte co-cultures prepared as described previously. Movies were aligned using the Cairn Image Splitter plugin in ImageJ. Graphs showing $\mathrm{F} / \mathrm{F}_{0}$ were plotted using Graph pad prism. Regions of interest were manually drawn and fluorescence was normalized to the first 10 frames before stimulation.

\section{Image and statistical analysis}

All experiments were performed on astrocytes/cell culture/mixed hippocampal astrocyte-neuro co-culture from at least three individual preparations. For all quantified experiments the experimenters were blind to the condition of the sample analyzed. All image analysis was performed blinded. Values are given as mean \pm standard error of the mean (SEM). Error bars represent SEM. Statistical analysis was performed in GraphPad Prism (version 8; GraphPad 
Software, CA, USA) or Microsoft Excel. All data was tested for normal distribution with D'Agostino \& Pearson test to determine the use of parametric (Student's t test, one-way ANOVA) or non-parametric (Mann-Whitney, Kruskal-Wallis) tests. When $\mathrm{p}<0.05$, appropriate post hoc tests were carried out in analyses with multiple comparisons and are stated in the figure legends.

\section{Electrophysiology}

Electrophysiology was carried out on embryonic hippocampal cultures on their tenth day in vitro. Cultures were prepared from nischarin WT or KO mice embryos at 16 days postfertilization. Recordings were carried out at room temperature $\left(20-21^{\circ} \mathrm{C}\right)$ with a HEPESbuffered extracellular solution mimicking cerebrospinal fluid (artificial cerebrospinal fluid, aCSF) containing (in mM): $140 \mathrm{NaCl}, 10 \mathrm{HEPES}, 10$ glucose, $2.5 \mathrm{KCl}, 2 \mathrm{CaCl}_{2}, 1 \mathrm{NaH}_{2} \mathrm{PO}_{4}$, $1 \mathrm{MgCl}_{2}$, pH 7.4 adjusted to with $\mathrm{NaOH}$, osmolarity 300 mOsm (oxygenated with $100 \% \mathrm{O}_{2}$ ). The solution was perfused at a flow rate of 3-4 $\mathrm{ml} / \mathrm{min}$ through the recording chamber using gravity-driven perfusion from syringe barrels $(60 \mathrm{ml})$ connected to individual tubes, which merged into a single outlet just prior to reaching the bath. Whole-cell patch-clamp recordings were made from astrocytes using a potassium gluconate based internal solution, containing (in mM): $130 \mathrm{~K}$-gluconate, $4 \mathrm{NaCl}, 10 \mathrm{HEPES}, 1 \mathrm{CaCl}_{2}$, 10 EGTA, $2 \mathrm{MgATP}, 0.5 \mathrm{Na}_{2} \mathrm{GTP}$ (adjusted to $\mathrm{pH} 7.1-7.2$ with $\mathrm{KOH}$, and osmolarity $285 \mathrm{mOsm})$. Alexa Fluor $594(20 \mu \mathrm{M})$ was added to each aliquot of internal solution on the day of the experiment. Astrocytes were recognised visually by their low contrast soma, with an angular morphology and stellate processes revealed by dye-filling and usually gap junctional coupling allowing dye spread to other nearby astrocytes (Fig. 4C).

\section{Recording glutamate uptake in astrocytes}

In order to record the glutamate uptake current from astrocytes, voltage-clamp recordings were made at the cell's resting potential (typically around $-90 \mathrm{mV}$ ). D-aspartate (200 $\mu \mathrm{M}$, Sigma) was used to evoke a transporter current, since it is taken up by glial glutamate transporters (Davies \& Johnston, 1976; Barbour et al., 1991; Furness et al., 2008) and may have less effect than glutamate on glutamate receptors. However, D-aspartate may activate NMDA receptors or inhibit AMPA/KA receptors (Gong et al., 2005), or release glutamate via heteroexchange on transporters (Volterra et al., 1996). Any resulting activation of glutamate receptors might cause membrane potential depolarisation, neuronal action potentials and a rise of $\left[\mathrm{K}^{+}\right]_{\mathrm{o}}$ into the extracellular space, which could evoke an inward current in astrocytes (which have a highly 
$\mathrm{K}^{+}$-permeable membrane: Meeks \& Mennerick, 2007). To prevent these effects we therefore supplemented the aCSF with a selection of blockers, which were present throughout the experiment: TTX to block action potentials (150nM, Tocris), a GABAA receptor blocker (bicuculline $10 \mu \mathrm{M}$, Sigma), NMDA receptor blockers (D-AP5 $50 \mu \mathrm{M}$, Tocris; (+)MK-801 10 $\mu \mathrm{M}$, Sigma; 5,7-DCK $10 \mu \mathrm{M}$, Sigma), an AMPA and kainate receptor blocker (NBQX $10 \mu \mathrm{M}$, Sigma), and an inwardly rectifying potassium channel blocker (barium chloride $200 \mu \mathrm{M}$, Sigma) which does not affect glutamate transport (Barbour et al., 1991). A non-transported glial glutamate transporter blocker (Shimamoto et al., 2004), TFB-TBOA (10 $\mu \mathrm{M}$, Tocris) was also used in some experiments to block the glutamate transporter current evoked by Daspartate. The size of the uptake current was calculated as the inward current recorded in Daspartate minus the average of the baseline currents measured before and after D-aspartate application (using Clampfit 10.4). Experiments were performed with the experimenter blinded to the genotype. 


\section{References}

AL AWABDH, S., GUPTA-AGARWAL, S., SHEEHAN, D. F., MUIR, J., NORKETT, R., TWELVETREES, A. E., GRIFFIN, L. D. \& KITTLER, J. T. 2016. Neuronal activity mediated regulation of glutamate transporter GLT-1 surface diffusion in rat astrocytes in dissociated and slice cultures. Glia, 64, 1252-64.

ALAHARI, S. K. 2003. Nischarin inhibits Rac induced migration and invasion of epithelial cells by affecting signaling cascades involving PAK. Exp Cell Res, 288, 415-24.

ALAHARI, S. K., LEE, J. W. \& JULIANO, R. L. 2000. Nischarin, a novel protein that interacts with the integrin alpha5 subunit and inhibits cell migration. J Cell Biol, 151, 1141-54.

ALAHARI, S. K., REDDIG, P. J. \& JULIANO, R. L. 2004. The integrin-binding protein Nischarin regulates cell migration by inhibiting PAK. EMBO J, 23, 2777-88.

ARANCIBIA-CARCAMO, I. L., YUEN, E. Y., MUIR, J., LUMB, M. J., MICHELS, G., SALIBA, R. S., SMART, T. G., YAN, Z., KITTLER, J. T. \& MOSS, S. J. 2009. Ubiquitin-dependent lysosomal targeting of GABA(A) receptors regulates neuronal inhibition. Proc Natl Acad Sci U S A, 106, 17552-7.

BANKER G, G. K. 1998. Culturing nerve cells.

BARBOUR, B. \& HAUSSER, M. 1997. Intersynaptic diffusion of neurotransmitter. Trends Neurosci, 20, 377-84.

BASSAN, M., LIU, H., MADSEN, K. L., ARMSEN, W., ZHOU, J., DESILVA, T., CHEN, W., PARADISE, A., BRASCH, M. A., STAUDINGER, J., GETHER, U., IRWIN, N. \& ROSENBERG, P. A. 2008. Interaction between the glutamate transporter GLT1b and the synaptic PDZ domain protein PICK1. Eur J Neurosci, 27, 66-82.

BREW, H. \& ATTWELL, D. 1987. Electrogenic glutamate uptake is a major current carrier in the membrane of axolotl retinal glial cells. Nature, 327, 707-9.

CHOI, D. W. 1987. Ionic dependence of glutamate neurotoxicity. J Neurosci, 7, 369-79.

CHOI, D. W., MAULUCCI-GEDDE, M. \& KRIEGSTEIN, A. R. 1987. Glutamate neurotoxicity in cortical cell culture. J Neurosci, 7, 357-68.

DANBOLT, N. C. 2001. Glutamate uptake. Prog Neurobiol, 65, 1-105.

DIAMOND, J. S. \& JAHR, C. E. 1997. Transporters buffer synaptically released glutamate on a submillisecond time scale. J Neurosci, 17, 4672-87.

DONG, S., BARANWAL, S., GARCIA, A., SERRANO-GOMEZ, S. J., EASTLACK, S., IWAKUMA, T., MERCANTE, D., MAUVAIS-JARVIS, F. \& ALAHARI, S. K. 2017. Nischarin inhibition alters energy metabolism by activating AMP-activated protein kinase. J Biol Chem, 292, 16833-16846.

EDELSTEIN, A., AMODAJ, N., HOOVER, K., VALE, R. \& STUURMAN, N. 2010. Computer control of microscopes using microManager. Curr Protoc Mol Biol, Chapter 14, Unit14 20.

GONZALEZ-GONZALEZ, I. M., GARCIA-TARDON, N., CUBELOS, B., GIMENEZ, C. \& ZAFRA, F. 2008. The glutamate transporter GLT1b interacts with the scaffold protein PSD-95. J Neurochem, 105, 1834-48.

HINDEYA GEBREYESUS, H. \& GEBREHIWOT GEBREMICHAEL, T. 2020. The Potential Role of Astrocytes in Parkinson's Disease (PD). Med Sci (Basel), 8.

IBANEZ, I., DIEZ-GUERRA, F. J., GIMENEZ, C. \& ZAFRA, F. 2016. Activity dependent internalization of the glutamate transporter GLT-1 mediated by beta-arrestin 1 and ubiquitination. Neuropharmacology, 107, 376-386.

JULIANO, R. L., REDDIG, P., ALAHARI, S., EDIN, M., HOWE, A. \& APLIN, A. 2004. Integrin regulation of cell signalling and motility. Biochem Soc Trans, 32, 443-6.

KELLER, B., LA HARPE, R. \& GARCIA-SEVILLA, J. A. 2017. Upregulation of IRAS/nischarin (I1-imidazoline receptor), a regulatory protein of mu-opioid receptor trafficking, in postmortem prefrontal cortex of long-term opiate and mixed opiate/cocaine abusers. Neurochem Int, 108, 282-286.

KUIJL, C., PILLI, M., ALAHARI, S. K., JANSSEN, H., KHOO, P. S., ERVIN, K. E., CALERO, M., JONNALAGADDA, S., SCHELLER, R. H., NEEFJES, J. \& JUNUTULA, J. R. 2013. Rac and Rab GTPases dual effector Nischarin regulates vesicle maturation to facilitate survival of intracellular bacteria. EMBO J, 32, 713-27. 
LEHRE, K. P. \& DANBOLT, N. C. 1998. The number of glutamate transporter subtype molecules at glutamatergic synapses: chemical and stereological quantification in young adult rat brain. $J$ Neurosci, 18, 8751-7.

LEVY, L. M., ATTWELL, D., HOOVER, F., ASH, J. F., BJORAS, M. \& DANBOLT, N. C. 1998a. Inducible expression of the GLT-1 glutamate transporter in a $\mathrm{CHO}$ cell line selected for low endogenous glutamate uptake. FEBS Lett, 422, 339-42.

LEVY, L. M., WARR, O. \& ATTWELL, D. 1998b. Stoichiometry of the glial glutamate transporter GLT-1 expressed inducibly in a Chinese hamster ovary cell line selected for low endogenous $\mathrm{Na+}$ dependent glutamate uptake. J Neurosci, 18, 9620-8.

LI, F., MA, H., WU, N. \& LI, J. 2016. IRAS Modulates Opioid Tolerance and Dependence by Regulating mu Opioid Receptor Trafficking. Mol Neurobiol, 53, 4918-30.

LI, S., WU, N., ZHAO, T. Y., LU, G. Y., WANG, Z. Y., LI, F. \& LI, J. 2019. The role of IRAS/Nischarin involved in the development of morphine tolerance and physical dependence. Biochem Biophys Res Commun, 512, 460-466.

LIM, K. P. \& HONG, W. 2004. Human Nischarin/imidazoline receptor antisera-selected protein is targeted to the endosomes by a combined action of a PX domain and a coiled-coil region. $J$ Biol Chem, 279, 54770-82.

MARIE, H., BILLUPS, D., BEDFORD, F. K., DUMOULIN, A., GOYAL, R. K., LONGMORE, G. D., MOSS, S. J. \& ATTWELL, D. 2002. The amino terminus of the glial glutamate transporter GLT-1 interacts with the LIM protein Ajuba. Mol Cell Neurosci, 19, 152-64.

MARTINEZ-VILLARREAL, J., GARCIA TARDON, N., IBANEZ, I., GIMENEZ, C. \& ZAFRA, F. 2012. Cell surface turnover of the glutamate transporter GLT-1 is mediated by ubiquitination/deubiquitination. Glia, 60, 1356-65.

MURPHY-ROYAL, C., DUPUIS, J., GROC, L. \& OLIET, S. H. R. 2017. Astroglial glutamate transporters in the brain: Regulating neurotransmitter homeostasis and synaptic transmission. J Neurosci Res, 95, 2140-2151.

MURPHY-ROYAL, C., DUPUIS, J. P., VARELA, J. A., PANATIER, A., PINSON, B., BAUFRETON, J., GROC, L. \& OLIET, S. H. 2015. Surface diffusion of astrocytic glutamate transporters shapes synaptic transmission. Nat Neurosci, 18, 219-26.

PEACEY, E., MILLER, C. C., DUNLOP, J. \& RATTRAY, M. 2009. The four major N- and C-terminal splice variants of the excitatory amino acid transporter GLT-1 form cell surface homomeric and heteromeric assemblies. Mol Pharmacol, 75, 1062-73.

PETERSON, A. R. \& BINDER, D. K. 2019. Post-translational Regulation of GLT-1 in Neurological Diseases and Its Potential as an Effective Therapeutic Target. Front Mol Neurosci, 12, 164.

SEKINE-AIZAWA, Y. \& HUGANIR, R. L. 2004. Imaging of receptor trafficking by using alphabungarotoxin-binding-site-tagged receptors. Proc Natl Acad Sci U S A, 101, 17114-9.

SKARNES, W. C., ROSEN, B., WEST, A. P., KOUTSOURAKIS, M., BUSHELL, W., IYER, V., MUJICA, A. O., THOMAS, M., HARROW, J., COX, T., JACKSON, D., SEVERIN, J., BIGGS, P., FU, J., NEFEDOV, M., DE JONG, P. J., STEWART, A. F. \& BRADLEY, A. 2011. A conditional knockout resource for the genome-wide study of mouse gene function. Nature, 474, 337-42.

SOGAARD, R., BORRE, L., BRAUNSTEIN, T. H., MADSEN, K. L. \& MACAULAY, N. 2013. Functional modulation of the glutamate transporter variant GLT1b by the PDZ domain protein PICK1. J Biol Chem, 288, 20195-207.

TANAKA, K., WATASE, K., MANABE, T., YAMADA, K., WATANABE, M., TAKAHASHI, K., IWAMA, H., NISHIKAWA, T., ICHIHARA, N., KIKUCHI, T., OKUYAMA, S., KAWASHIMA, N., HORI, S., TAKIMOTO, M. \& WADA, K. 1997. Epilepsy and exacerbation of brain injury in mice lacking the glutamate transporter GLT-1. Science, 276, 1699-702.

TONG, G. \& JAHR, C. E. 1994. Block of glutamate transporters potentiates postsynaptic excitation. Neuron, 13, 1195-203.

UNDERHILL, S. M., WHEELER, D. S. \& AMARA, S. G. 2015. Differential regulation of two isoforms of the glial glutamate transporter EAAT2 by DLG1 and CaMKII. J Neurosci, 35, 5260-70. 
WADICHE, J. I., AMARA, S. G. \& KAVANAUGH, M. P. 1995a. Ion fluxes associated with excitatory amino acid transport. Neuron, 15, 721-8.

WADICHE, J. I., ARRIZA, J. L., AMARA, S. G. \& KAVANAUGH, M. P. 1995b. Kinetics of a human glutamate transporter. Neuron, 14, 1019-27.

WITCHER, M. R., PARK, Y. D., LEE, M. R., SHARMA, S., HARRIS, K. M. \& KIROV, S. A. 2010. Threedimensional relationships between perisynaptic astroglia and human hippocampal synapses. Glia, 58, 572-87.

ZERANGUE, N. \& KAVANAUGH, M. P. 1996. Flux coupling in a neuronal glutamate transporter. Nature, 383, 634-7.

ZOU, S., PITA-ALMENAR, J. D. \& ESKIN, A. 2011. Regulation of glutamate transporter GLT-1 by MAGI1. J Neurochem, 117, 833-40. 
Figure 1 bioRxiv preprint doi: https://doi.org/10.1101/2020.11.28.402222; this version posted November $28,2020$. The copyright holder for this
preprint (which was not certified by peer review) is the author/funder, who has granted bioRxiv a license to display the preprint in A $111 \quad$ perpetuity. It is made avaigole under aCC-BY-ND 4.0 International license.

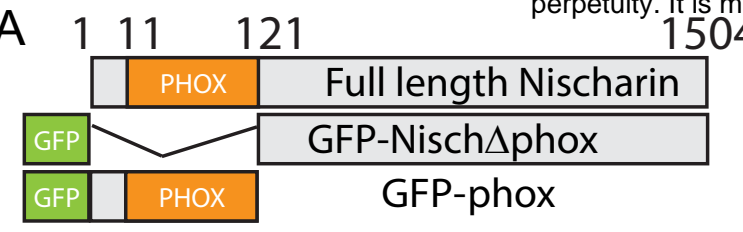
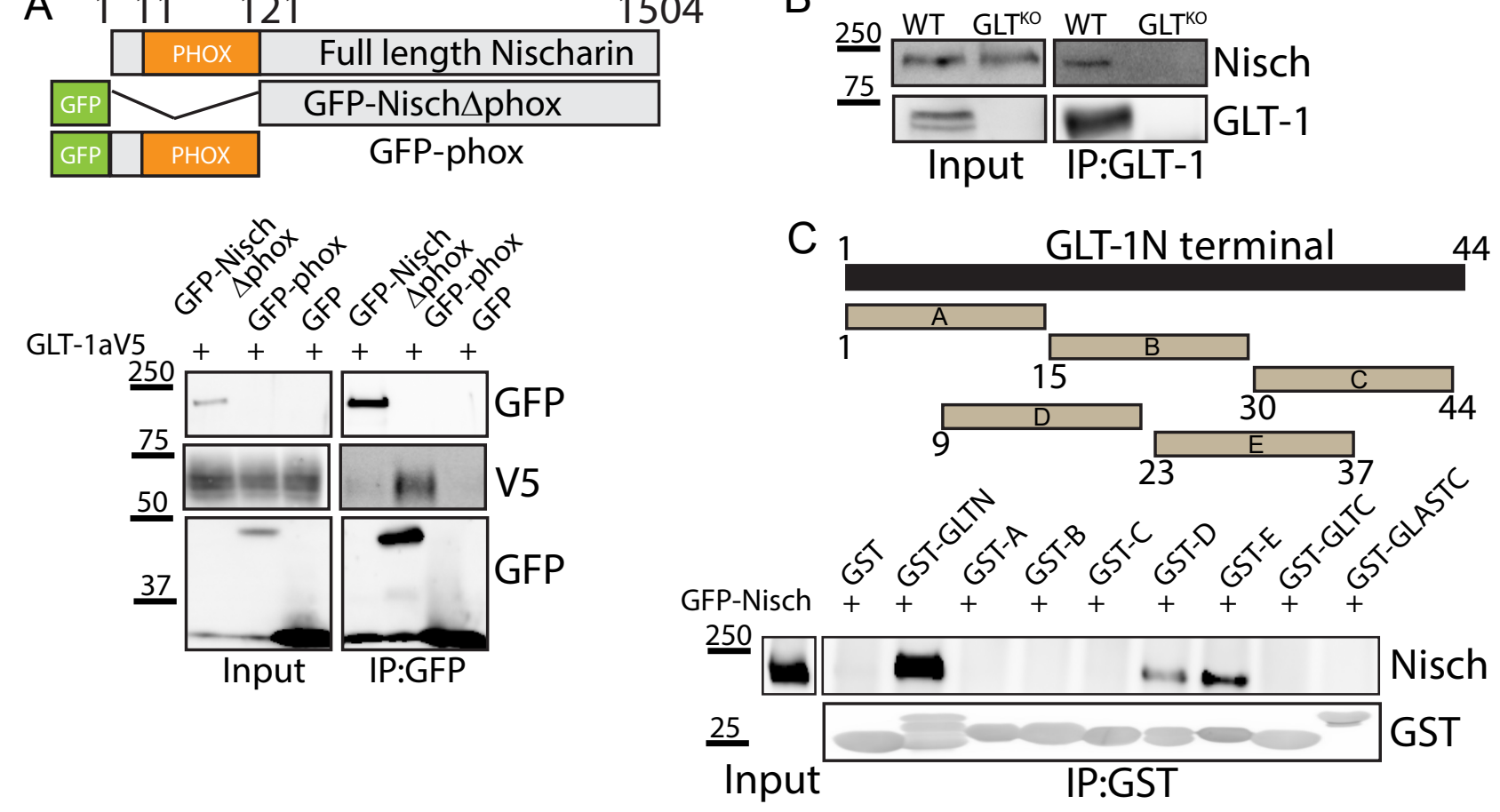


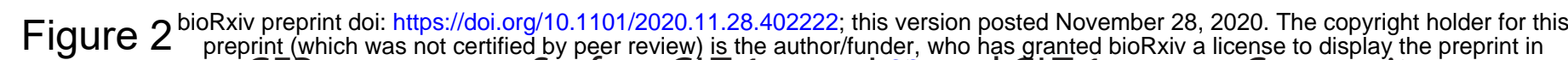

A GFP

B

C

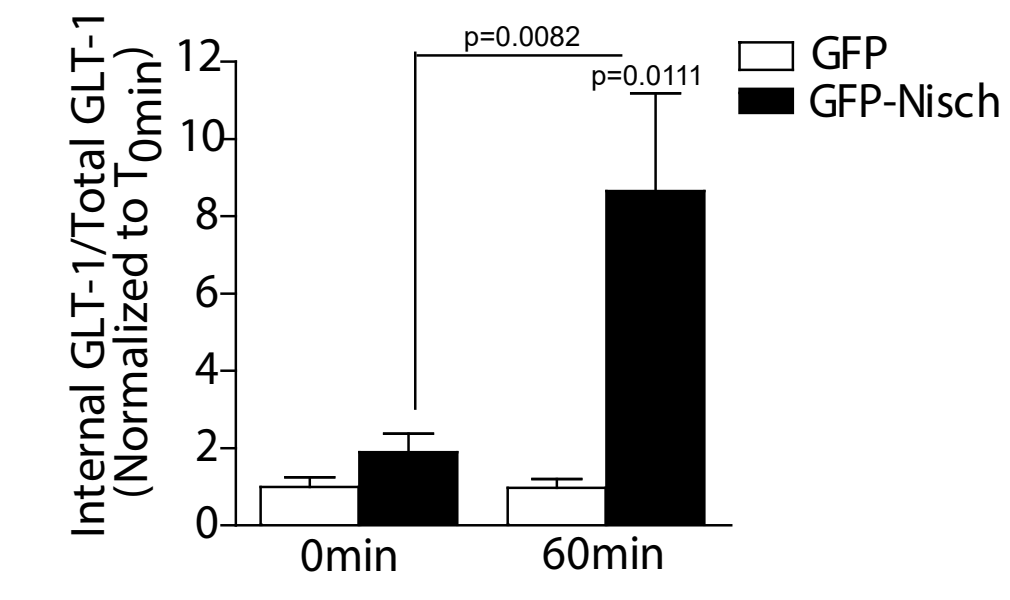
$\mathrm{T}_{60 \mathrm{mi}}$

$60 \mathrm{~min}$
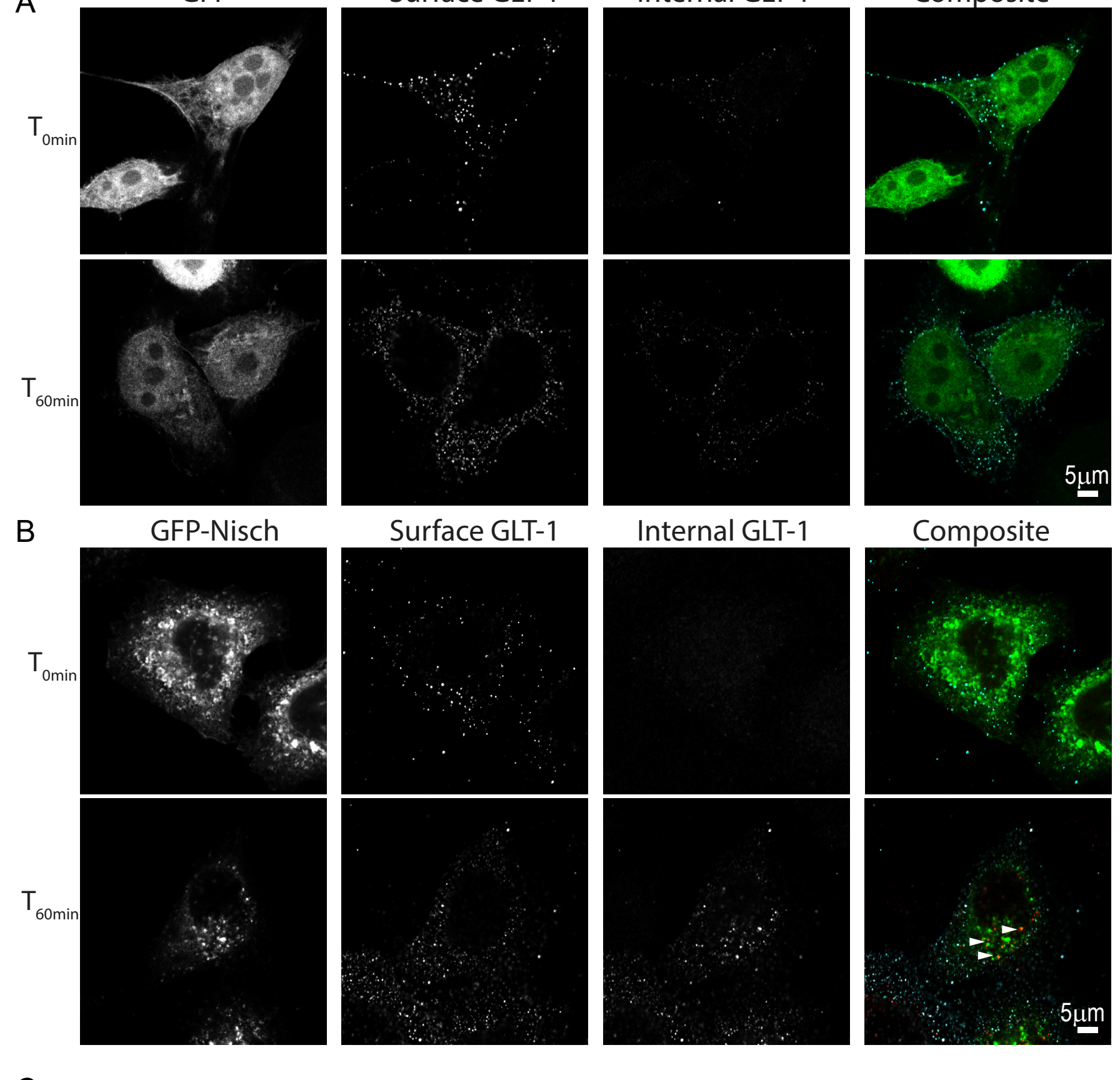

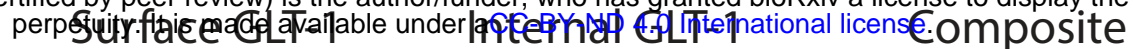

Surface GLT-1

Internal GLT-1

\section{Composite}

$5 \mu \mathrm{m}$
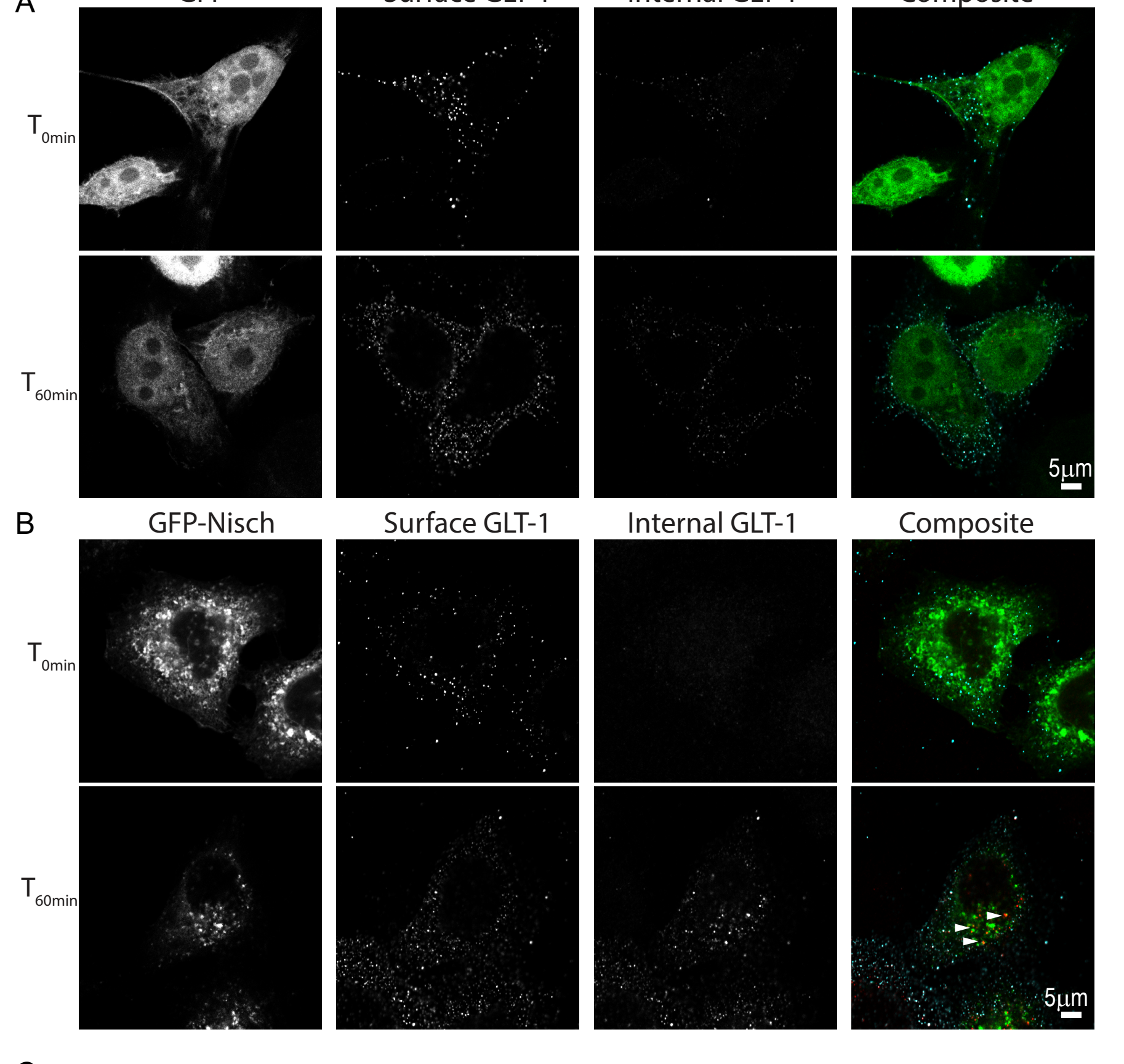

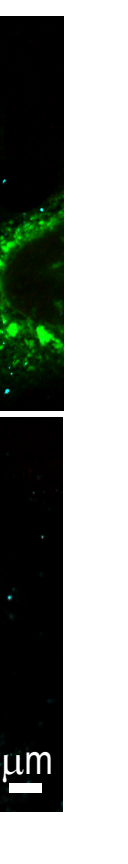


Figure 3

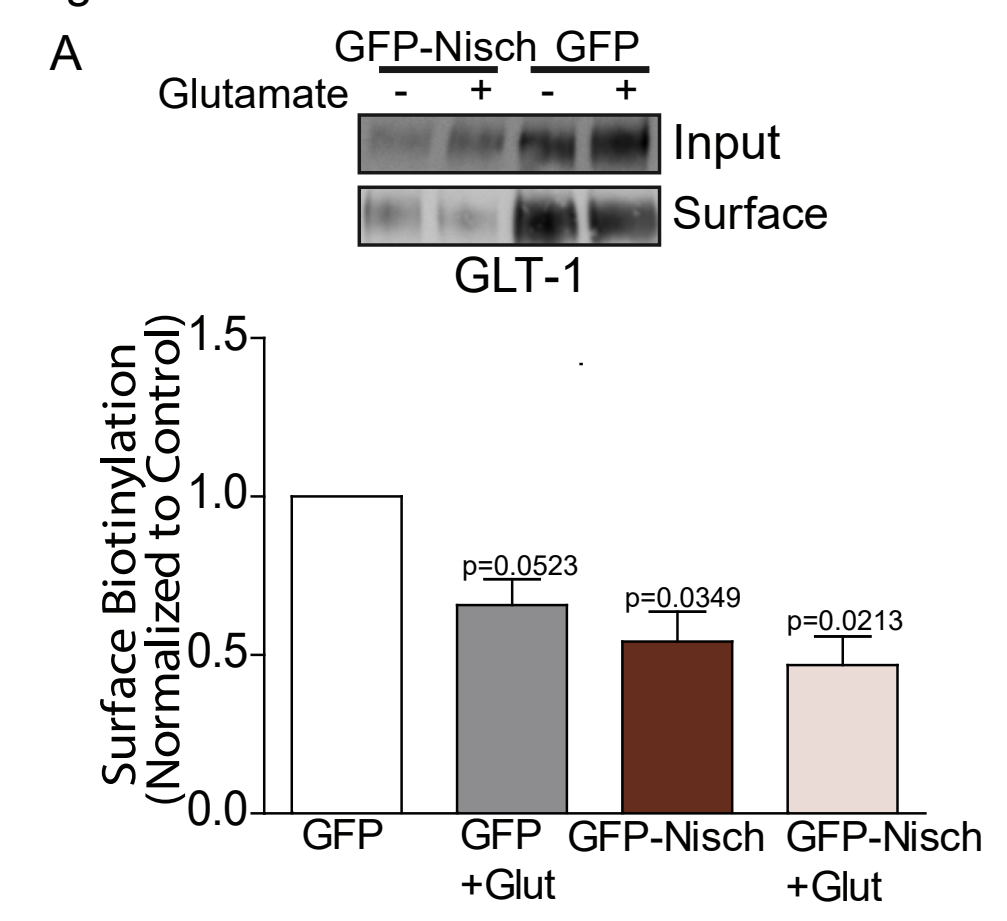

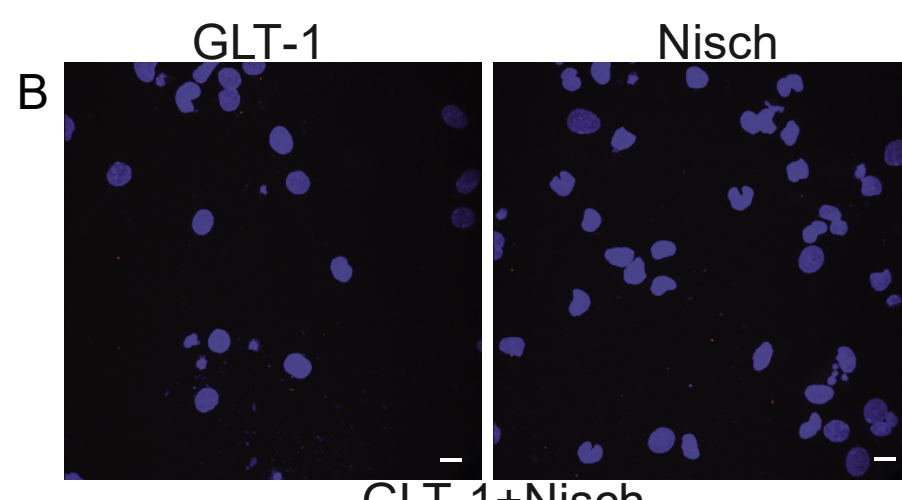

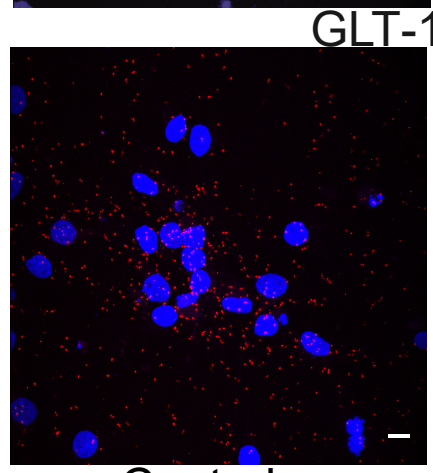

Control

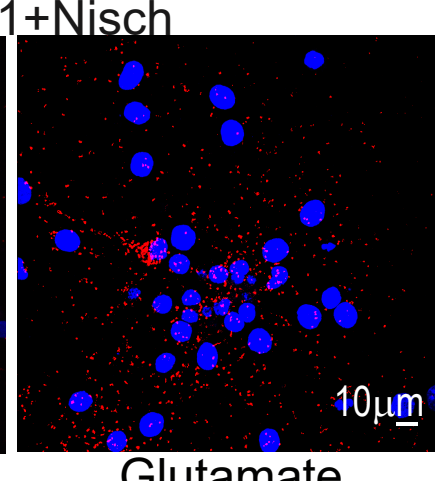

Glutamate

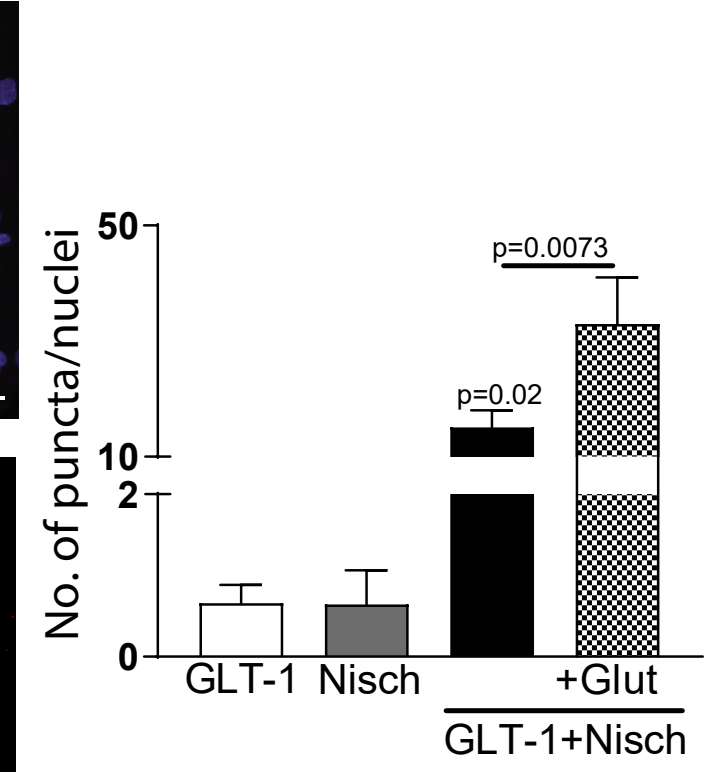

Glutamate

C

क़

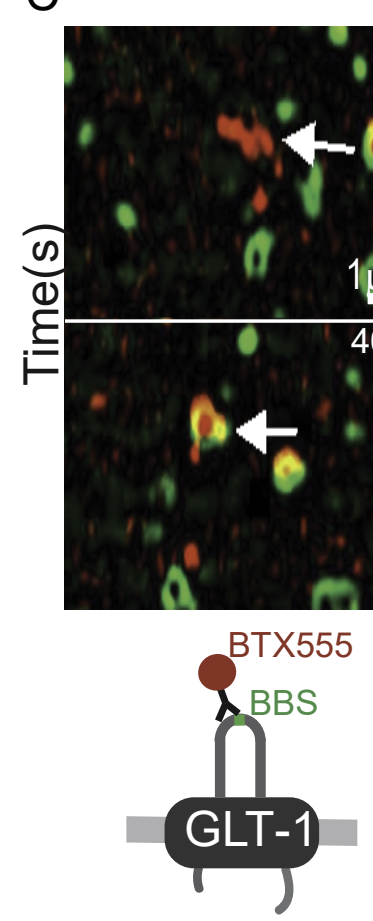

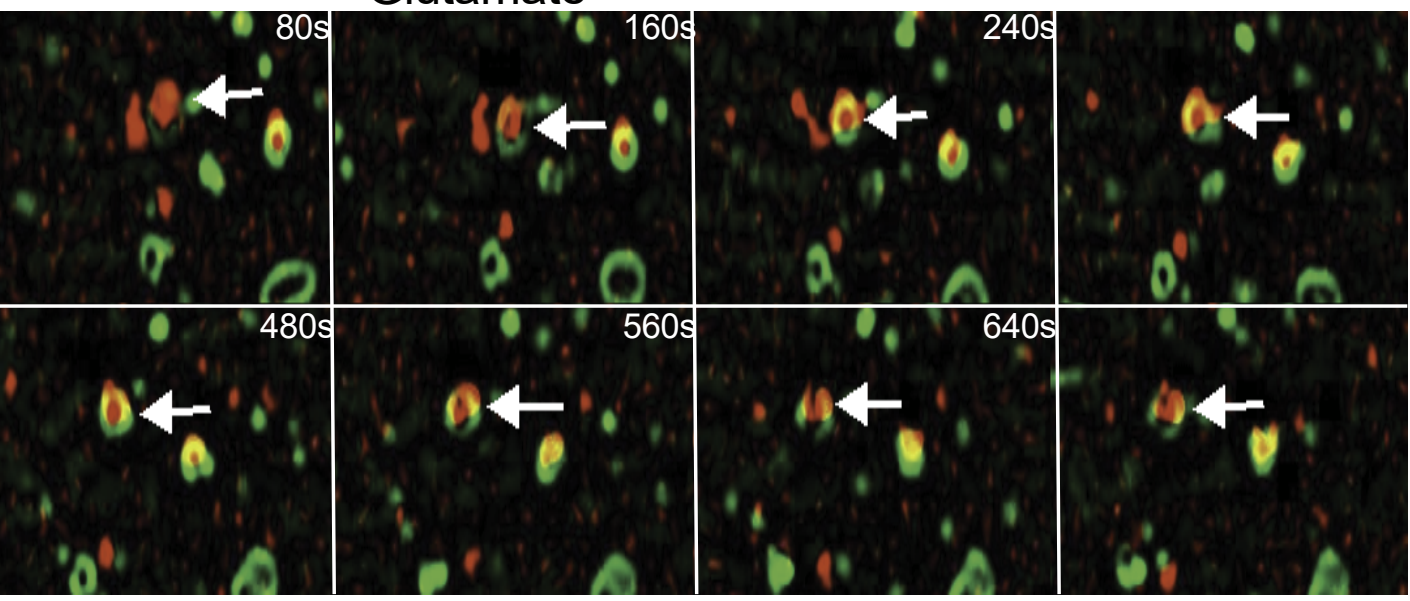

$$
\text { 号 }
$$

GFP-Nisch
GLT-1aBBS

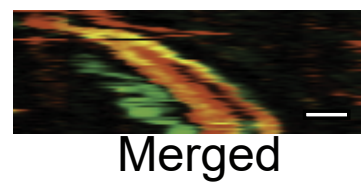

D

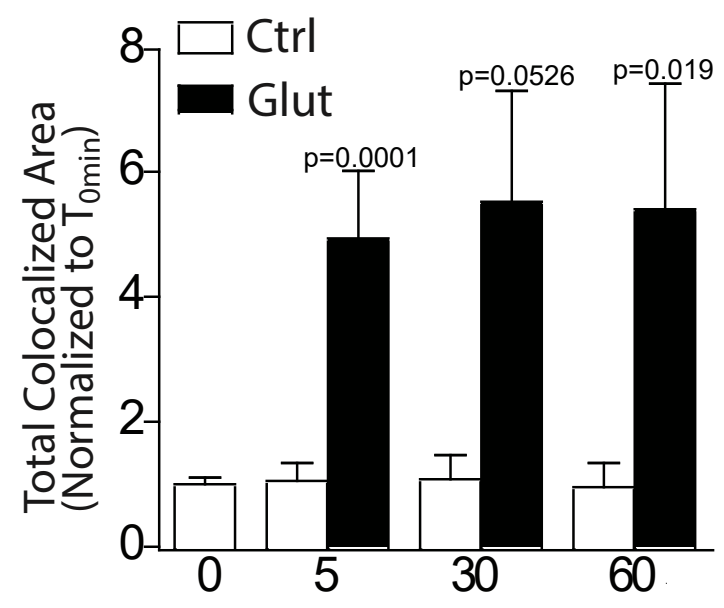


